PACLink and PACLoan was a desire to experiment in statewide cooperation and resource sharing to give any library in Utah access to information databases without having to individually purchase them. The universities are part of an 11-library consortium called the Utah College Library Council comprised of all higher education institutions in the state that have libraries. These three universities are the largest in the consortium and each has the NOTIS library management system. The other eight sites have the Dynix system. Dynix and NOTIS are working together to guarantee interoperability of both systems.

\title{
Barcoding: Tedious project or community party?
}

Broome Community College (BCC) Learning Resources staff turned a tedious barcoding project into a community party. During the holiday break, 95 retired and current BCC faculty, staff, and students participated in a barcoding party resulting in the barcoding of 65,584 titles in preparation for participation in the SUNY Library Automation Project.

Barcode volunteers were recruited from the college community to help "bring the LRC into the 21st century." Articles were written for the staff newsletter and the student newspaper. The college president invited all college employees to participate. The director of Learning Resources demonstrated the benefits of automation to student and faculty groups. Phi Theta Kappa, the student gov-

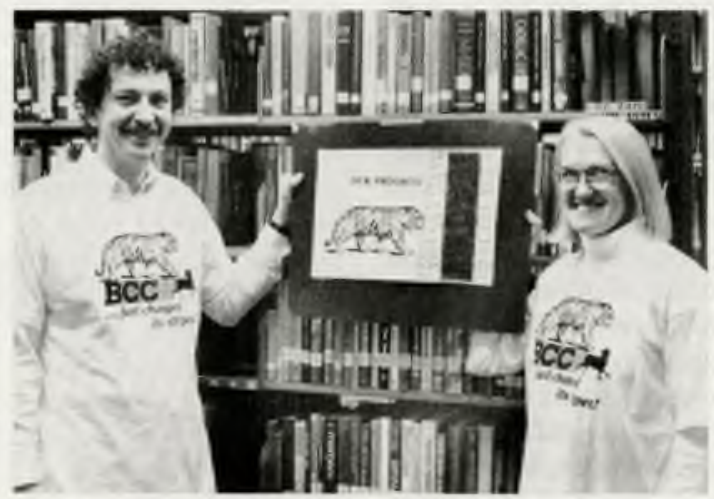

Larry Jenkins and Wanda Johnston display BCC's barcoding project progress chart and t-shirts. coffee donated by the college food service, ate donuts donated by area merchants, and socialized.

The collection was divided into sections. This enabled teams to work without interruption from other teams, while able to see and communicate with each other, occasionally engaging in mini-contests. A progress chart, updated daily, kept teams enthused about their progress.

The student government and the faculty/ student associations contributed "BCC just changed its stripes!" t-shirts designed by the Publications Center. These tshirts and certificates of appreciation were given to all barcoding participants. In addition, once the project was completed, participating staff and volunteers celebrated with pizza and cake.

Can barcoding be changed from a tedious task to a community party? Broome Community College proved it can. Volunteer comments included:

"I'm doing this for my children."

"I thought I would only help out one morning, but this is so much fun I'll be back tomorrow."

"I'm sorry the project is done."-Wanda $K$. Jobnston, director of learning resources, Broome Community College, Binghamton, New York 